First publ. in: After the wall: Family adaptations in East and West Germany /J. Youniss (ed.). San Francisco: Jossey-Bass, 1995, pp. 39-56

Empirical data comparing East and West German adolescents' socialization conditions and present tendencies for aggression and altruism show certain differences but also similarities that must be tested for stability in ongoing longitudinal studies.

\title{
Prosocial and Antisocial Motivation of Adolescents in East and West Germany
}

\author{
Gisela Trommsdorff, Hans-Joachim Kornadt
}

In this chapter, we attempt to advance the discussion about the role macrosocial conditions play in individual development, especially in the development of pro- and antisocial behavior. In this attempt, we seek to clarify the effects of socialization conditions in the former GDR on the development of social motives, conditions for the development of social motives and inner structure, the development of aspects of pro- and antisocial motivation (taking into account the roots they may have in common and their situationspecific activation), and the effects of the drastic political and economic changes following the unification of East and West Germany on the development of social motives. This requires clarification of the problems and risks adolescents face during drastic socioeconomic change. Increasing or stabilizing differences in social motives between East and West German adolescents may constitute a serious obstacle not only to the psychological process of unification, but also to the process of adapting to the massive sociopolitical changes currently taking place.

Ideally, these goals would be achieved by means of a longitudinal study, making use of a quasinatural experimental design. Here, however, we present only the data from our first measurement of the social motives of East and West German adolescents, which we will study by focusing on the socialization conditions before the unification.

This study was supported by a grant from the Deutsche Forschungsgemeinschaft (German Society for the Advancement of Scientific Research). It was carried out with the help of H.-D. Schmidt, Marion Hessel-Scherf, Brigitte Husarek, and Corinna Schmude. 
So far, little is known about the different effects of socialization on the social development of adolescents in East and West Germany. A comparison of adolescent development is especially interesting because both Germanies shared the same cultural history for centuries but then went through very different sociopolitical changes during the last five decades. However, the possible effects of socialization in the former GDR are confounded with those of the dramatic changes after the unification of the two parts of Germany. We have yet to discover what effects the radical changes in the institutions had on individual orientations. The changes entail opportunities as well as burdens (Schmidt and Heckhausen, 1994; Trommsdorff, 1994b, 1994c). In any event, the development of adolescents in East Germany involves different conditions and developmental demands than that of adolescents in West Germany.

\section{Conditions of Socialization in East and West Germany}

Detailed descriptions of the socialization and educational system in the GDR illustrate that a collectivistic ideology of child rearing was linked with a pervasive system of control and sanctions in all social institutions (Melzer, Ferchhoff, and Neubauer, 1990; Schmidt, 1992; Schmidt, Schaarschmidt, and Peter, 1991; Henrich, 1990). Individual decision making and planning were hindered by strict regulations governing all areas of living.

The goal for child rearing was to achieve a socialist personality. The official educational programs were based on the assumption of a tabula rasa model of human development (Schmidt, 1992). Accordingly, child rearing and education were considered a task of the state. Therefore, the family was largely deprived of its former function of socializing the children. This was implemented by having infants enrolled in Kinderkrippen (the state-controlled all-day nurseries) as early as possible, usually in the second half of the first year. On average, about 80 percent of all infants were institutionalized in Kinderkrippen. The entire educational system was based on the official ideology of the socialist government. The children were to learn to conform to the rules of the party and accept the party's authority and any state regulations, including the renunciation of private property, mobility, and individual freedom. Moreover, the socialist personality was to be prepared to fight against the enemies of the working class, for socialism, and for the state's notion of peace.

These goals are well-defined in the educational programs for teachers and other agents of socialization, such as the virtually obligatory youth organization Freie Deutsche Jugend (Free German Youth).

All pupils attended Einheitsschule, the socialist comprehensive school, for ten years. After that, a select group of pupils (about 8 percent) could attend Erweiterte Oberschule (senior high school) for two years, which terminated with the Abitur (a final examination). The selection of students who were allowed to attend universities was controlled by the state and was based on the criteria of the planned economy. Customarily, one's past political activities were 
also a criterion for selection. Demonstration of conformity with the party was thus a precondition for one's future success and for certain privileges, such as being selected to attend a university or to get a job in a field of one's own interest. Consequently, a relatively safe future time perspective was transmitted because with a secure job, social status and material security could be expected.

Because commitment to the party was rewarded, one may assume that conformity was highly valued. However, this did not guarantee individuals' internalization of transmitted values; on the contrary, only a minority of the population of the former GDR was really committed to the official ideology and the majority only purported to conform to the party while actually remaining neutral, indifferent, or sometimes in secret opposition. Therefore, this official description of socialization in the former GDR may fail to illustrate what actually occurred. Several authors claim that, in the former GDR, the state ideology of child rearing did not acknowledge socialization in the family. However, the family may have functioned as a niche for private retreat and personal security from the totalitarian system. There, one could establish close emotional relations, personal freedom, and individual thinking. However, the extent to which this was the case is still unclear.

Nevertheless, the family in the former GDR was structured differently from that in West Germany. Because of the official ideology of gender equality and the fundamental necessity for the GDR to activate all human capital, nearly all women worked. The establishment of the all-day nurseries enabled the mothers to go back to work soon after childbirth, whether they wanted to or not. Therefore, mothers spent much less time with their children in East as compared to West Germany, where only 48 percent of mothers with children under six years of age work. The effects of early disruption of the mother-child relation by the all-day institutionalization of infants plus the artificial social settings influenced by political propaganda have not been clarified yet.

Socialization in West Germany. The situation in West Germany was very different. First, very different attitudes and values related to child rearing were in place. In general, socialization conditions are structured in such a way that children are independent and internalize the values of individuality and independence.

Parents in West Germany try hard not to display authoritarian behavior and not to refer to their authority. Goals for development and socialization of children have become increasingly important in Germany in recent years (Klages, 1984; Trommsdorff, 1993b). This has also been an official goal of educational institutions and their related programs at least since the 1960s. However, this value has induced insecurity on the part of parents who wonder how to behave; for example, they are uncertain when to tell their children to conform and obey. It seems difficult for them to differentiate between authoritarian and authoritative styles of socialization (Zumkley-Münkel, 1994). The need to set limits and regulate the child's behavior contradicts the goal of not enforcing rules. 
Decisions with respect to the adolescent's future life and career are not made by central authorities. Children and adolescents make such decisions together with their parents and friends. Children and adolescents also make their own decisions about which peer group they want to belong to. Consequently, such individual decision making constitutes an important aspect of child development.

Youth groups in the former GDR were organized and controlled by the party according to the goals of the party. In contrast, peer groups in West Germany are usually established as a result of individual preferences, aiming to achieve individuality and autonomy for their members.

To summarize, in West Germany, the pluralistic, democracy-based system was organized to promote individualistic values and independence by focusing on children's and adolescents' individual needs, goals, and capabilities and by allowing them to mistrust and oppose authorities. In contrast, the former GDR sought to implement a socialist Utopia, making use of authoritarian devices and pressure to conform.

\section{Development of Pro- and Antisocial Motivation}

Aggression and prosocial action are social motivations directed at opposite goals. In the case of aggression, the goal of action is to harm another person. In the case of prosocial action, the goal is to prevent harm and to increase another person's well-being. Up until now, these two forms of social action have been studied separately in the literature. Only recently have these forms of social action been discussed as different but interrelated social orientations (Zahn-Waxler, Chapman, and Radke-Yarrow, 1986).

Staub (1986) and Kornadt (1982a, 1992, 1994) discuss aggression and altruism from a theoretical point of view that considers both as different aspects of social motivation and points out the role of attachment in early child development. Feshbach and Feshbach (1986) conceive of aggression and altruism as related components of the personality. They emphasize the necessity of studying the development of both motives in relation to each other. Here, the role of emotions, especially of empathy and anger, and their changing function in the course of development are of particular importance for the development of social motivations. It is assumed that prosocial behavior and aggression are based on motive systems with the same structure that differ due to the qualitatively different affects, cognitive evaluations, and goals of the two types of behavior.

Although secure attachment should give rise to the development of prosocial motivation, insecure attachment should affect the development of aggression. According to Kornadt (1994), both the attachment-based working models and the related emotional experiences constitute the cognitive and affective basis for the development of aggression and prosocial motivation.

Aggression. The current state of aggression research and its different theoretical approaches have been summarized by Kornadt (1992). Although neuro- 
physiological and ethological research neglects the learning conditions, the psychology of learning research overlooks the biological roots, cognitive processes, and interaction effects of socialization and learning during personality development. In social psychological research, in which the subjective interpretations of situational factors are viewed as conditions for aggressive behavior, stable individual differences and their development are neglected. Motivation theories fill this gap. Kornadt's (1982a, 1992) motivation theory of aggression and aggression inhibition is based on several empirical, including cross-cultural, studies. The theory explains that different components become systematically related in the process of development and that certain processes can be activated to determine aggressive behavior. It became evident that individual differences exist not only globally, but also with respect to specific components of the complex motive system. One component is anger, the emotional basis for the development of aggression. Other components include the interpretation of a frustrating situation as having been caused by malevolent intentions, or one's moral views on aggression. The amazingly high stability in individuals' aggression (see Olweus, 1979; Zumkley, 1992) supports the disposition standpoint although the stimulation and functioning of the motive system is situation-specific.

Authoritarian and cold child-rearing practices are conducive to the development of aggression (Berkowitz, 1993; Kornadt, 1982a). Parental neglect and rejection, external threat, and rigidity promote the development of aggression (Kornadt, 1982a; Olweus, 1980). In cross-cultural studies, maternal warmth and responsivity were related to low aggressiveness of children (Kornadt, 1988; Kornadt and others, 1992).

Altruism. Here, altruism and aggression are considered different aspects of the same motive that share some cognitive and affective characteristics in their development and situation-specific activation (Staub, 1986). For example, affective processes such as empathy can activate prosocial motivation and block aggression motivation.

To date, studies on prosocial behavior have generally been carried out from a cognitive point of view, pointing out, for example, the role of social norms and moral values. However, recently, the role of affective processes, especially the function of empathy (sympathy) for prosocial motivation, has been referred to in several developmental studies in the United States (Eisenberg, 1986; Hoffman, 1982). Observational and cross-cultural studies by Trommsdorff and her coworkers have shown that prosocial behavior depends to a large extent on empathy (feeling and partially identifying with the other person). This has been demonstrated for German (Friedlmeier, 1993; Trommsdorff, 1993a), Russian (Kienbaum, 1993), and Japanese children (Trommsdorff, 1993a, 1994a).

These recent studies have shown that a motivation theoretical analysis of prosocial behavior is particularly fruitful with regard to the understanding of prosocial action. Altruistically motivated action (helping behavior that promotes another person's well-being) is to be differentiated from norm-oriented 
and from egoistically motivated action (helping behavior that conforms to social norms and promotes one's own well-being). In line with this reasoning, Karylowski $(1982,1988)$ distinguishes between two forms of prosocial motivation. Endocentric motivation is the attempt to diminish one's own guilt feelings or to promote a self-evaluation as fulfilling social norms; exocentric motivation is the attempt to improve the other person's situation. Recognizing the different forms of prosocial motivation should allow us to assess the emotional, empathic forms of prosocial motivation on one hand and the cognitive and norm-oriented forms of prosocial motivation on the other hand.

Individual differences depend on past socialization experiences. Parents' child-oriented, responsive behavior promotes the child's secure attachment and related working models, which constitute a necessary condition for the development of altruism. In recent studies, controlling and simultaneously warm, responsive child rearing and the parent's prosocial behavior (model) were found to be relevant for the development of prosocial motivation (Feshbach, 1987; Hoffman, 1984; Staub, 1986; Trommsdorff, 1991, 1993a). Socialization practices that direct the attention of the child toward his or her own well-being support the development of endocentric but hinder exocentric prosocial motivation (Karylowski, 1982, 1988). In contrast, other-oriented induction (Hoffman, $1982,1984)$ is a technique that focuses children's attention on the other person, causing them to perceive the consequences of their behavior for the other person and thus fostering an altruistic prosocial motivation. In the same line, Trommsdorff (1994a) has shown that children of responsive mothers develop a higher level of altruistic motivation. According to these findings, it can be assumed that the development and stability of social motives are based on patterns of social interaction in early development, including the mother's responsiveness and the child's attachment.

\section{Research Questions}

We started with the question of the differences in socialization in East and West Germany and their possible effects on personality development. One must be aware that even though formal differences in socialization conditions in East and West Germany seem obvious, the effects thereof are not clear. Differences that exist on the aggregate level do not necessarily exist on the individual level, especially on the basis of only single points of measurements. For example, there may be individual differences in the way the person has experienced socialization conditions that have been described as typical for East and West Germany. The official educational ideology of the GDR and its impact may have been supplemented by informal social networks.

This study is the beginning of a longitudinal project in which comparative data on adolescents from the two parts of Germany are used to derive hypotheses to be assessed in the future. In this study, we focus on the assumed effects of early childhood experiences and the subsequent long-lasting effects of interaction patterns that may have taken place in the two very different 
sociopolitical contexts. Our working hypotheses for the present study were as follows:

- From an attachment theoretical view, East German children presumably have developed less secure attachment because, being sent to all-day nurseries, they were separated from their parents at a very early age. Accordingly, more insecure attachment might be expected for East as compared to West German adolescents.

- Less empathy (presumably a precondition for less prosocial behavior) and more anxiety and anger (presumably preconditions for aggressive reactions) might be expected more from East German than West German adolescents. This tendency may have developed due to socialization in an environment that tended to exaggerate in-group-out-group differences and to spread feelings of hostility toward nonsocialist countries through authoritarian socialization and military jargon such as "fighting the enemy." The society of the former GDR built a self-image of being threatened by capitalism. Furthermore, people grew up perceiving their activities to be under the party's control. The Bespitzelung (spying) conducted by the Staatssicherheitsdienst (state security police) represented a permanent threat, even at one's workplace. Hostility toward out-group members was embedded in feelings of insecurity and a low sense of trust in other people, especially in an official context. On the other hand, solidarity and cooperation with family members and friends were highly valued.

Presumably, this political atmosphere induced feelings of suspicion and insecurity. The higher amount of politicization of all areas of life along with the high level of suspicion and mistrust in East Germany should block the empathic basis for prosocial motivation. Accordingly, the empathic aspect of prosocial behavior may be less pronounced among East German than among West German adolescents.

- The high level of mistrust, suspicion, and hostility should entail a higher level of aggression motivation for East German than West German adolescents. This hypothesis also seems plausible because education programs in the former GDR did not treat the issue of interpersonal conflicts and aggression in informal encounters (Schmidt, 1994). In contrast, in West Germany, education programs discussed methods of openly dealing with interpersonal conflicts and aggression.

- A motivation-theoretical approach does not necessitate the assumption of only global personality differences but rather allows us to assume situationspecific differences. Therefore, it is necessary to specify the subjective meaning of action-relevant situations. Accordingly, from a motivation theoretical point of view, one should assume that differences and similarities exist between East and West German adolescents depending on the domain-specific meaning of certain situations, actions, and action consequences. The domainspecific meaning should depend on the adolescents' past socialization and present experiences in the process of adaptation to extensive sociopolitical transformations. 


\section{Sample}

Three sites were selected for this study. We did not want to restrict our sample to East and West Berlin. Therefore, we sought out regional areas that were comparable, at least with respect to their size and economic situation. We studied sixty adolescents (thirty males and thirty females) in Brandenburg in East Germany as well as thirty-five adolescents (seventeen males and eighteen females) in Saarbrücken and forty-five adolescents (fifteen males and thirty females) in Konstanz in West Germany. The adolescents were all about sixteen years old and in the tenth grade of a Gymnasium (college preparatory school). All subjects participated voluntarily and with the consent of their respective parents, school principals, and state ministries of educational affairs.

\section{Instruments Used to Measure Antisocial Motivation}

Two instruments were used to measure aggression: a semiprojective test (A-TAT) and a questionnaire (SAS). These instruments were developed from Kornadt's (1982a) theory of the aggression motive.

The Aggression TAT is a modified version of the original TAT developed for measuring the aggression motive and the inhibition of aggressive impulses (Kornadt, 1982b). The instrument consists of eight picture-stories that provoke fantasies that are relevant to aggression. A theory-based scoring key is used to categorize qualitative responses with high reliability. In addition to the quantitative evaluation, contents (particular aggression themes, courses of action, causes of anger, goals) can be measured (Komadt and others, 1992).

The SAS consists of fifty-two items. Twenty-seven items measure aggression and twelve items measure aggression inhibition (five-point scales). In addition, there are thirteen neutral items. On the basis of factor analyses, several subscores of the SAS were used as indicators to measure emotional and cognitive components of aggression and aggression inhibition.

\section{Instruments Used to Measure Prosocial Motivation}

In order to measure endocentric and exocentric orientation, Karylowski's (1982) Prosocial Motivation Inventory (PMI) was used. The PMI allowed us to differentiate between two goals of action, one more egoistic and the other more altruistic (benefiting oneself versus benefiting the other). This instrument was originally used to study Polish pupils. We had it translated and back-translated and modified some aspects. Our final version contained four picture-stories (one female and one male version). The stories describe a person who is in some sort of trouble (a victim) and are followed by a list of statements (twelve items) giving reasons for helping and not helping the victim. Helping involves the investment of personal resources, such as money, time, and fun. Half of the items contained egoistic and the other half altruistic reasons. For each of the 
four situations, adolescents were asked to choose whether they agreed or did not agree with each of the items.

Attachment was measured by means of a modified version of the Adult Attachment Scale (AAS) developed by Collins and Read (1990). This procedure is based on the instrument used by Hazan and Shaver (1987) that operationalizes the typology of the three attachment styles (secure, secure-avoidant, insecureambivalent) introduced by Ainsworth, Blehar, Waters, and Wall (1978) for adults. Adolescents were to indicate which of the three descriptions they felt characterized them best. After our pilot studies, eleven of the original eighteen iterns were retained. Factor analyses produced the factors intimacy (proximity, dependency) and avoidance. We added one level to the response scale in order to match the five-level response mode of the other instruments used.

Optimism was measured by the Life Orientation Scale (LOT) constructed by Scheier and Carver (1985). It consisted of eight items that were to be answered on a five-point scale $(1=$ strongly agree, $5=$ do not agree at all $)$. This instrument has been used in several studies and was found to have high validity and reliability. It was translated, back-translated, and pretested before final use.

\section{Results: Antisocial Motivation}

For the A-TAT, our findings revealed significantly less aggression inhibition in East German than in West German adolescents $(F=16.27, p<.001)$. We also found a strong gender effect for net aggression (aggression minus aggression inhibition). East German females were more aggressive than West German females, East German males were more aggressive than West German males, and females in general were less aggressive than males $(F=4.38, p<.05)$.

For the global scores on aggression as measured by the SAS, no significant differences between East and West German adolescents were found on aggression or aggression inhibition (see Table 3.1). However, the results on specific components of the SAS revealed significant differences with respect to certain aggression motive scores. East German youth showed significantly more aggressive reactions when frustrated than West German youth $(F=5.92, p<$ $.05)$. This was due to the East German males $(F=12.09, p<.05)$. Here, a significant interaction effect was found $(F=5.71, p<.05)$.

We also found significant differences on the aggression inhibition components. Results on emotional reactions inhibiting aggression showed a tendency that East German adolescents reported less shame and guilt than West German adolescents $(F=3.06, p<.10)$. In addition to this main effect, effects of gen$\operatorname{der}(F=2.75, p<.10)$ and interaction effects $(F=6.48, p<.01)$ also occurred. This result was mainly due to the lower amount of shame and guilt displayed by the East German males. Also, East German adolescents demonstrated less prosocial action tendencies inhibiting aggression than West German adolescents $(F=3.12, p<.10)$. 
Table 3.1. Antisocial and Prosocial Motivation of East and West German Adolescents

\begin{tabular}{|c|c|c|c|c|}
\hline \multirow[b]{2}{*}{ Variables } & \multicolumn{2}{|c|}{ East } & \multicolumn{2}{|c|}{ West } \\
\hline & $\begin{array}{l}\text { Female } \\
(N=30)\end{array}$ & $\begin{array}{c}\text { Male } \\
(N=30)\end{array}$ & $\begin{array}{l}\text { Female } \\
(N=48)\end{array}$ & $\begin{array}{c}\text { Male } \\
(N=32)\end{array}$ \\
\hline \multicolumn{5}{|l|}{ Aggression } \\
\hline \multicolumn{5}{|l|}{ TAT } \\
\hline Aggression mhibition & $\begin{array}{l}1.97 \\
(1.33)\end{array}$ & $\begin{array}{c}1.67 \\
(1.24)\end{array}$ & $\begin{array}{c}3.04 \\
(1.53)\end{array}$ & $\begin{array}{c}2.56 \\
(1.48)\end{array}$ \\
\hline Net aggression & $\begin{array}{l}3.03 \\
(2.68)\end{array}$ & $\begin{array}{l}3.77 \\
(2.54)\end{array}$ & $\begin{array}{l}2.38 \\
(2.50)\end{array}$ & $\begin{array}{l}3.50 \\
(2.63)\end{array}$ \\
\hline \multicolumn{5}{|l|}{ SASa; partial scores } \\
\hline Anger & $\begin{array}{l}3.75 \\
(0.43)\end{array}$ & $\begin{array}{l}3.16 \\
(0.82)\end{array}$ & $\begin{array}{l}3.36 \\
(0.86)\end{array}$ & $\begin{array}{l}3.37 \\
(0.79)\end{array}$ \\
\hline Aggressive goals & $\begin{array}{l}3.08 \\
(0.97)\end{array}$ & $\begin{array}{c}3.23 \\
(1.17)\end{array}$ & $\begin{array}{l}2.56 \\
(0.86)\end{array}$ & $\begin{array}{c}2.71 \\
(0.92)\end{array}$ \\
\hline Aggressive reaction & $\begin{array}{l}2.19 \\
(0.65)\end{array}$ & $\begin{array}{c}2.81 \\
(0.93)\end{array}$ & $\begin{array}{l}2.06 \\
(0.62)\end{array}$ & $\begin{array}{r}2.29 \\
(0.75)\end{array}$ \\
\hline \multicolumn{5}{|l|}{ Aggression inhibition } \\
\hline Prosocial behavior ${ }^{b}$ & $\begin{array}{l}1.75 \\
(0.69)\end{array}$ & $\begin{array}{l}1.88 \\
(0.96)\end{array}$ & $\begin{array}{l}1.54 \\
(0.71)\end{array}$ & $\begin{array}{l}1.64 \\
(0.77)\end{array}$ \\
\hline Shame and guilt ${ }^{\mathrm{a}}$ & $\begin{array}{l}2.67 \\
(0.78)\end{array}$ & $\begin{array}{l}1.97 \\
(0.98)\end{array}$ & $\begin{array}{l}2.54 \\
(0.81)\end{array}$ & $\begin{array}{c}2.67 \\
(1.06)\end{array}$ \\
\hline \multicolumn{5}{|l|}{$\begin{array}{l}\text { Prosocial Motivation } \\
\text { Karylowskic }\end{array}$} \\
\hline Exocentric & $\begin{array}{c}0.85 \\
(0.12)\end{array}$ & $\begin{array}{c}0.81 \\
(0.14)\end{array}$ & $\begin{array}{c}0.85 \\
(0.18)\end{array}$ & $\begin{array}{r}0.90 \\
(0.13)\end{array}$ \\
\hline Endocentric & $\begin{array}{c}0.64 \\
(0.15)\end{array}$ & $\begin{array}{c}0.57 \\
(0.21)\end{array}$ & $\begin{array}{l}0.73 \\
(0.19)\end{array}$ & $\begin{array}{c}0.74 \\
(0.20)\end{array}$ \\
\hline Nonempathic & $\begin{array}{c}0.44 \\
(0.21)\end{array}$ & $\begin{array}{c}0.55 \\
(0.23)\end{array}$ & $\begin{array}{c}0.44 \\
(0.19)\end{array}$ & $\begin{array}{c}0.47 \\
(0.19)\end{array}$ \\
\hline
\end{tabular}

$0=$ do not agree; $5=$ strongly agree.

b $0=$ strongly agree; $5=$ do not agree.

$\mathrm{co}_{0}=\mathrm{no}_{1} 1=$ yes.

\section{Results: Prosocial Motivation}

The results on altruism, as measured by Karylowski's Prosocial Motivation Inventory, showed that East as compared to West German adolescents showed fewer endocentric reactions $(F=15.96, p<.001)$. Also, East German males showed a tendency toward fewer exocentric reactions than West German males $(F=2.48, p<.10)$. Furthermore, less empathy was shown by males (especially East German males) than by females $(F=4.54, p<.05)$.

For the sample as a whole, prosocial motivation and aggression correlated negatively (endocentric: $r=-.19, p<.05$; exocentric: $r=-.13, p<.10$ ). In the same line, prosocial motivation and aggression inhibition correlated positively (endocentric: $r=.33, p<.001$; exocentric: $r=.25, p<.01$ ). Also, a positive correlation between nonempathic responses and aggression inhibition $(r=.24$, 
$p<.01)$ and a negative correlation between nonempathic responses and aggression inhibition $(r=-.21, p<.01)$ occurred. The same pattern holds for the East and West German samples taken separately.

We did not find any significant differences with respect to our indicators of attachment. However, our findings did reveal some interesting relations between attachment and social motives. Some of the expected correlations between attachment and aggression and the emotional quality of prosocial motivation occurred with respect to the sample as a whole. Aggression and aggression inhibition (SAS) were both positively correlated with avoidance of intimate relationships $(r=.22, n=139, p<.01)$. In the same line, a preference for intimate relationships (secure attachment) was negatively related to aggres$\operatorname{sion}(r=-.24, n=139, p<.01)$.

Although no relation between aggression and avoidance or preference for intimate relationship occurred for the East German youth, these relationships were highly significant for the West German youth $(r=.37, p<.001$; and $r=$ $-30, p<.01 ; n=79)$. The difference between these correlations for the East and the West German sample was significant $(z=1.90, p<.10$ and $2.11, p<.05)$.

The Life Orientation Scale showed that East German adolescents were less optimistic than West Germans $(F=4.97, p<.05)$. This result was mainly due to the pessimistic orientation of the East German females.

\section{Summary}

West German adolescents showed more prosocial tendencies than East Germans. Although the global scores of aggression as measured by the SAS showed no differences, more detailed analyses based on components of aggression measured by this questionnaire showed more activation of anger, aggressive action tendencies, and aggressive reactions to frustration for East German adolescents. All these components are conditions for aggression according to the aggression theory. Also, the emotion-based aggression inhibition tendencies (shame, guilt, and prosocial action) were stronger among West German adolescents. In the same line, aggression inhibition was higher for West German youth on the TAT. The resultant aggression motive (net aggression) on the TAT showed an overall gender effect, with males scoring higher than females. However, East German girls scored higher than West German girls. Results on life orientation showed that East German adolescents, especially females, were more pessimistic than West Germans.

\section{Discussion}

This exploratory study was designed to pose questions about possible differences and similarities in prosocial and antisocial motivation of East and West German adolescents. We refrained from formulating specific hypotheses because the socialization conditions in the different sociopolitical systems in East and West Germany were quite complex and not the same for each adolescent in our sample. 
We assumed that the strict, authoritarian child-rearing methods in the educational institutions and the general hostility transmitted by the party ideology with respect to the extrafamilial environment would contribute to the foundation of a hostile view and interpretation of the world. They would also lead to the formation of less interpersonal trust and helping in social relationships (outside the family), thereby resulting in the development of aggression. One might therefore assume that, on the aggregate level, East German adolescents would show higher aggression and lower aggression inhibition than West German adolescents. Furthermore, less prosocial motivation, and especially less altruistic motivation, would be expected from East German adolescents.

On the other hand, in reaction to the intrusive state, East German adolescents might have close emotional relations within the family, thereby producing compensatory effects. Solidarity and cooperation in informal social relationships might also have been established as a reaction to the totalitarian, controlling state. The compensatory function of the family for the East German adolescents may be much stronger than is assumed here, and may have produced wide interindividual differences. The proximate family environment, giving emotional and social support to the child and adolescent, may have compensated for the experience of insecurity and hostility outside the family in other social contexts. If so, the expected differences in social motivation between East and West Germans might even out. Possible effects of the transformation process cannot be discussed here; this is being studied in our longitudinal project.

We found significant differences in the expected direction on the basis of the TAT. East German adolescents showed lower aggression inhibition. Because the TAT focuses more on the emotional and motivational quality of aggression, it can be assumed that social desirability tendencies and superficial cognitive preferences are less relevant here. In the same line of reasoning, we found significant differences in the expected direction for the items of the SAS questionnaire that measure more emotional and motivational qualities of aggression, such as pursuing aggressive goals or experiencing aggression after frustration or experiencing anger related to frustration. From a motivation theoretical point of view, these emotion-based aspects are most relevant to aggressive acts.

The study revealed significant differences on the dimension of emotions and action, but those on the cognitive dimension were not significant. Therefore, the total scores of the SAS did not produce significant differences. These results highlight the necessity to study not only the cognitive components of the aggression motive, but the emotional components as well, and to start from a domain-specific approach when studying social motivation.

A similar interpretation holds for the differences in aggression inhibition and in prosocial motivation. The items selected from the SAS demonstrate that for action tendencies and emotion-based prosocial behavior such as shame and guilt, West German adolescents scored higher than East German adolescents. As for the results from the Karylowski questionnaire, the differences are in the 
same direction. West German adolescents preferred more prosocial action; they exhibited more normative self-enhancing prosocial values (higher endocentric scores) and more empathy-based prosocial action (higher exocentric scores).

Furthermore, we found significant gender differences that had not been expected; these can be explained post hoc by referring to the politically enforced gender equality in the former GDR and the situation after the collapse of the GDR, which increased insecurity and risks, especially for girls because of the changing socioeconomic situation. Especially East German females seem to be affected negatively by past socialization and present transformation processes. They showed the highest degree of pessimism of all the groups. Also, they were most likely to feel anger and frustration, which resulted in more aggressive tendencies than were found in West German females. One may speculate that the enormous changes faced by East German adolescents induce gender-specific reactions. These changes may be challenges for males, but connote socioeconomic and psychological threats to females.

The gender-specific effects of socialization in the former GDR before and after its collapse still have not been sufficiently clarified (Nickel, 1990; Trommsdorff, 1992). The continued existence of the traditional female role in the former GDR (the double role of working mother), despite the official genderrole equality, as compared to the "emancipated" female role in West Germany and the related socialization experiences for girls (such as the role model of mothers) may have different effects on the development of boys and girls in East Germany.

Our results must be interpreted in light of the small sample and measurements used. The measures are approximations but they reveal differences. We were not able to measure early attachment in childhood but instead had to use a questionnaire that measures attachment indirectly by ascertaining positive and negative attitudes toward intimate adult relations (Hazan and Shaver, 1987). Interestingly, emotional development and attachment were not topics of research in the former GDR.

However, early childhood attachment cannot be measured by the questionnaire we used. The adult attachment attitudes questionnaire used here may have different meanings for the two samples. For example, the slogans of solidarity associated with all official social activities in the former GDR may have induced a superficial preference for attachment on the cognitive level of verbally expressed attitudes in East German adolescents, whereas the motivational quality of attachment rooted in the emotional experiences of early childhood may be different.

East German adolescents presumably experienced less secure attachment in their early childhood due to early separation from their mothers. However, this early childhood attachment cannot be measured by the questionnaire we used.

One might argue that the measurement of prosocial motivation by Karylowski $(1982,1988)$ may not reflect present concerns and problems of East German adolescents and may have more to do with social desirability than with actual motivation. Even if this were the case, we may have measured differences in prosocial value orientation that are a part of the motive system. 
Also, the interpretation of our results must take into account the fact that since the collapse of the former GDR, East German youth have undergone significant experiences of turmoil and change even in their proximate environment. The drastic socioeconomic and political changes in East Germany and the ongoing effects of the transformation process may proceed in the same direction as those presumably resulting from the socialization experienced during the existence of the former GDR, confronting adolescents with frustrating experiences and feelings of insecurity. This may increase the East German adolescents' tendency toward aggression. It remains to be seen how the proximate environment, like the family, will react to these new challenges and risks. In the event of disruption and conflict in the family resulting from the unemployment or identity crises of parents who no longer feel embedded in society, no increase in altruism and prosocial motivation can be expected. If close emotional bonds exist within the family, prosocial tendencies, especially for in-group interactions, may occur.

We do not want to interpret the differences or similarities as direct effects of the adolescents' different cultural environments or as a direct outcome of the different macrostructures of the political and economic systems, but rather to understand how the processes of social development and the effects of the ongoing socioeconomic transitions are experienced by adolescents.

We face a special opportunity to study the development of social motivation in a sociopolitical period of transition. At first glance, the comparison of East and West German samples seems to be ideal subject matter for a quasinatural experimental analysis. The two Germanies share a centuries-old common history and tradition but, during the last forty years, have experienced very different political systems that should have constituted the socialization context for adolescents. However, socialization takes place on different levels of society-the macro-, meso-, and micro-levels-which presumably interact with each other. Therefore, the extent to which we can make predictions based on different macro-level structures about different effects of the socialization process remains unclear.

At least from a psychological point of view, one has to conceive of the socialization conditions on different levels of structural complexity so that we can clearly define what kind of psychological processes can be expected to influence these different levels (Trommsdorff, 1994a, 1995). However, this means that we have to return to the individual person who interprets his or her environment in a certain way and acts on that environment according to his or her individual goals, values, and abilities.

Individual families and people have reacted in different ways because they did not identify with the former GDR to the same extent. This should result in different forms of interpretation and readiness for coping. In future research, these conditions should be differentiated more carefully.

The basis for development of social motives is seen here in the long-lasting effects of early socialization experiences, especially the interaction processes formed from early childhood on. We also assume that later influences may support or diminish the prevalent social motivation. Therefore, we interpret our results as having been influenced by specific socialization conditions in the two 
Germanies, which may still be influential in many ways even after unification. At the same time, we also take into account the individual's interpretation of these environmental contexts. These processes can also lead to intraregional differences in East and in West Germany, which may cloud interregional differences between East and West German samples.

Also, a study on adolescents always involves personality development in progress. Thus, we cannot generalize and anticipate stability over time in the observations made. Furthermore, development is taking place in a complex sociopolitical context that has been changing dramatically for East Germans. They have experienced different socialization goals during transition from childhood to adolescence and transition from adolescence to adulthood. Their own transitional experience coincides with drastic sociopolitical changes that are affecting the proximate environment, possibly including their family (as in parents' unemployment or divorce).

One may assume that on the basis of past socialization experiences, the ongoing socioeconomic changes result in a higher degree of vulnerability to risking (and experiencing) antisocial behavior, whereas opportunities to act (and be treated) prosocially and to find security in mutual social solidarity are less common (Trommsdorff, 1994b, 1994c). It may well be that some people are more vulnerable to anger and aggressive reactions, especially under psychological stress. On the other hand, one may deal with stress by securing social support and solidarity, which encourages a tendency for prosocial action. So far, however, we do not know how these action tendencies are related to each other on an individual level because we can only report on differences on an aggregate level here. In line with our results, a recent study on the personality differences between East and West German adolescents and young adults by Hänsgen, Kasielke, Schmidt, and Schwenkmezger (1992) has demonstrated higher distress of anger and anxiety for East German subjects. These differences were most pronounced for females. In the same line, Sturzbecher (1993) has reported more aggressive intentions for samples of East German youth.

In further research, the subjective meaning of the massive socioeconomic and political changes in East Germany must be studied with respect to the formation of the subjective theories of the person in context and the inherent factors of prosocial and antisocial tendencies. Such studies are of practical relevance because the stabilization of the differences in social motives between East and West German youth presumably affect individual and social adjustment and, furthermore, political and economic processes in East and West Germany.

\section{References}

Ainsworth, M. D., Blehar, M. C., Waters, E., and Wall, S. Patterns of Attachment. A Psychological Study of the Strange Situation. Hillsdale, N.J.: Erlbaum, 1978.

Berkowitz, L. Aggression. Its Causes, Consequences and Control. New York: McGraw-Hill, 1993

Collins, N. L., and Read, S. J. "Attachment, Working Models, and Relationship Quality." Journal of Personality and Social Psychology, 1990, 58, 644-663. 
Eisenberg, N. Altruistic Emotion, Cognition, and Behavior. New York: Erlbaum, 1986.

Feshbach, N. D. "Parental Empathy and Child Adjustment/ Maladjustment." In N. Eisenberg and J. Strayer (eds.), Empathy and its development. Cambridge: Cambridge University Press, 1987.

Feshbach, S., and Feshbach, N. D. "Aggression and Altruism. A Personality Perspective." In C. Zahn-Waxler, E. M. Cummings, and R. Iannotti (eds.), Altruism and Aggression. Cambridge: Cambridge University Press, 1986.

Friedlmeier, W. Entwicklung von Empathie, Selbstkonzept und Prosozialem Handeln in der Mittleren Kindheit [The Development of Empathy, Self-Concept, and Prosocial Orientation in Middle Childhood]. Konstanz, Germany: Hartnung-Gorre, 1993.

Hänsgen, K. D., Kasielke, E., Schmidt, L. R., and Schwenkmezger, R. "Ostdeutsche und Westdeutsche im Vergleich: Emotionalität und Objektive Persönlichkeitsvariablen [Comparison of East and West Germany: Emotionality and Objective Personality Measures]." Zeitschrift fur Klinische Psychologie, Psychopathologie und Psychotherapie, 1992, 40, $346-363$

Hazan, C., and Shaver, P. "Romantic Love Conceptualized as an Attachment Process." Journal of Personality and Social Psychology, 1987, 52, 511-524.

Henrich, R. Der Vormundschaftliche Staat [The State as Caretaker]. Leipzig, Germany: Kiepenheuer, 1990

Hoffman, M. L. "Development of Prosocial Motivation: Empathy and Guilt." In N. Eisenberg (ed.), The Development of Prosocial Behavior. New York: Academic Press, 1982.

Hoffman, M. L. "Parent Discipline, Moral Internalization, and Development of Prosocial Motivation." In E. Staub, D. Bar-Tal, J. Karylowski, and J. Reykowski (eds.), Development and Maintenance of Prosocial Behavior. New York: Plenum Press, 1984.

Karylowski, J. "Two Types of Altruistic Behavior. Doing Good to Feel Good or to Make the Other Feel Good." In V.J. Derlega and J. Grzelak (eds.), Cooperation and Helping Behavior. Theories and Research. New York: Academic Press, 1982.

Karylowski, J. "Focus of Attention and Altruism: Endocentric and Exocentric Sources of Altruistic Behavior." In N. Eisenberg and J. Strayer (eds.), Empathy and its Development. Cambridge: Cambridge University Press, 1988.

Kienbaum, J. Empathisches Mitgefuhl und Prosoziales Verhalten Deutscher und Sowjetischer Kindergartenkinder [Empathy and Prosocial Behavior in German and Soviet Kindergarteners]. Regensburg, Germany: Roderer Verlag, 1993.

Klages, H. Wertorientierungen im Wandel. Rückblick, Gegenwartsanalysen, Prognosen [Changes in Value Orientations: Past, Present, and Future]. Frankfurt: Campus, 1984.

Kornadt, H.-J. Aggressionsmotiv und Aggressionshemmung (Band 1) Motivation and Inhibition in Aggression]. Bern, Switzerland: Huber, 1982a.

Kornadt, H.-J. Aggressionsmotiv und Aggressionshemmung (Band 2) [Motivation and Inhibition in Aggression]. Bern, Switzerland: Huber, $1982 \mathrm{~b}$.

Kornadt, H.-J. "Entwicklungsbedingungen Unterschiedlicher Aggressivität in Japan und Deutschland: Beitrag des Kulturvergleichs zur Motivationstheorie [Developmental Conditions: Differences in Aggression Between Japan and Germany]." Psychologische Beiträge, $1988,30,344-374$.

Kornadt, H.-]. "Einflusse der Erziehung auf die Aggressivitätsgenese [Influences on the Development of Aggression]." In H.J. Komadt (ed.), Aggression und Frustration als Psychologisches Problem, Band 2 [Aggression and Frustration as Psychological Problems]. Darmstadt, Germany: Wissenschaftliche Buchgesellschaft, 1992.

Kornadt, H.-J. "Development of Pro- and Antisocial Motivation in Cross-Cultural Comparison." Technical Report no. 70. Saarbrücken, Germany: University of the Saar, 1994.

Kornadt, H.-J, Hayashi, T., Tachibana, Y., Trommsdorff, G., and Yamauchi, H. "Aggressiveness and its Developmental Conditions in Five Cultures." In S. Iwawaki, Y. Kashima, and K. Leung (eds.), Innovations in Cross-Cultural Psychology. Selected Papers from the Tenth International Conference of the International Association for Cross-Cultural Psychology, Nara, Japan. Amsterdam: Swets \& Zeitlinger, 1992. 
Melzer, W., Ferchhoff, W, and Neubauer, G. (eds.). Jugend in Israel und in der Bundesrepublik. Sozialisationsbedingungen im Kulturvergletch |Youth in Israel and Germany. Cultural Comparison of Socialization]. Weinheim, Germany: Juventa, 1990.

Nickel, H. M. "Geschlechtersozialisation in der DDR oder: Zur Rekonstruktion des Patriarchats im Realen Sozialismus [Gender Socialization: The Reconstruction of Patriarchy in Socialisml." Zeitschrift fur Sozialisationsforschung und Erziehungssoziologie, 1990, 1 (supplement).

Olweus, D. "Stability of Aggressive Reaction Pattems in Males: A Review." Psychological Bulletin, $1979,86,852-875$.

Olweus, D. "Familial and Temperamental Determinants of Aggressive Behavior in Adolescent Boys: A Causal Analysis." Developmental Psychology, 1980, 16, 644-660.

Scheier, M. F., and Carver, C. S. "Optimism, Coping, and Health: Assessment and Implications of Generalized Outcome Expectancies." Health Psychology, 1985, 4, 219-247.

Schmidt, H.-D. "Frühe Kindheit in der Ehemaligen DDR im Spannungsfeld Familie/Krippe [Early Childhood in the Framework of Family and Preschool in the Former DDR]." Psychologie in Erziehung und Unterricht, 1992, 39, 149-155.

Schmidt, H.-D. "Erziehungskonzepte vor der Wend [Educational Concepts Regarding the Transformation of the GDR]." Paper presented at the Conference on Transformation Processes in Childhood, Berlin, Dec. 2, 1994.

Schmidt, H.-D., and Heckhausen, J. "Entwicklungspsychologische Transformationsforschung - Ziele, Grundlagen, Konsequenzen [Transformation of Research in Developmental Psychology: Goals, Bases, and Consequences]." In G. Trommsdorff (ed.), Psychologische Aspekte des Sozio-Politischen Wandels in Ostdeutschland [Psychological Aspects of Social-Political Change in East Germany]. Berlin: DeGruyter, 1994

Schmidt, H.-D., Schaarschmidt, U., and Peter, V. (eds.). Dem Kinde Zugewandt. Uberiegungen und Vorschlage zur Erneuerung des Bildungswesens [Thoughts and Suggestions on the Renewal of Education]. Hohengehren, Germany: Schneider Verlag, 1991

Staub, E. "A Conception of the Determinants and Development of Altruism and Aggression: Motives, the Self, and the Environment." In C. Zahn-Waxler, E. M. Cummings, and R. Iannoui (eds.), Altruism and Aggression. Cambridge: Cambridge University Press, 1986.

Sturzbecher, D. "Jugendliche in Brandenburg-Auf der Suche nach Orientierung Adolescents in Brandenburg: In Search of Meaning]. Vortrag zur Fachkonferenz Entstehung von Fremdenfeindlichkeit-Die Verantwortung von Politik und Medien IOrigins of Xenophobia: The Responsibility of Politics and the Medial. Unpublished manuscript. Potsdam, Germany, 1993.

Trommsdorf, G. "Child-Rearing and Children's Empathy." Perceptual and Motor Skills, 1991 , $72,387-390$.

Trommsdorff, $G$. "Forschung zur Geschlechtsspezifischen Sozialisation in der Damaligen DDR [Research on Sex-Specific Socialization in the Former DDR]." Berliner Joumal der Soziologie, 1992, 3, 389-398.

Trommsdorf, $G$. "Kulturvergleich von Emotionen beim Prosozialen Handeln [Cultural Comparisons of Emotions in Prosocial Behavior]." In H. Mandl, M. Dreher, and H.J Komadt (eds.), Entwicklung und Denken im Kulturellen Kontext [Development and Thinking in Cultural Context]. Gottingen, Germany: Hogrefe, 1993 a.

Trommsdorff, $G$. "Value Change in Germany." Japanstudien. Jahrbuch des Deutschen Instituts für Japanstudien der Philipp-Franz-von Siebold Stiftung. Band 4 [Yearbook of the German Institute for Japanese Studies of the Philipp-Franz-von Siebold Foundation]. Munich: Iudicium, 1993b.

Trommsdorff, G. "Empathy and Prosocial Action in Cultural Environments: A CrossCultural Analysis." In T. Kindermann and J. Valsiner (eds.), Development of PersonContext Relations. Hillsdale, N.J.: Erlbaum, 1994a.

Trommsdorff, G. (ed.). Psychologische Aspekte des Sozio-Politischen Wandels in Ostdeutschland [Psychological Aspects of Social-Political Change in East Germany]. Berlin: DeGruyter, $1994 \mathrm{~b}$.

Trommsdorff, G. "Psychologische Probleme bei den Transformationsprozessen in Ostdeutschland [Psychological Problems in the Transformation Process in East Germany]." 
In $G$. Trommsdorff (ed.), Psychologische Aspekte des Sozio-Politischen Wandels in Ostdeutschland [Psychological Aspects of Social-Political Change in East Gemany]. Berlin: DeGruyter, $1994 \mathrm{c}$.

Trommsdorff, G. "Parent-Adolescent Relations in Changing Societies: A Cross-Cultural Study." In P. Noack, M. Hofer, and Y. Youniss (eds.), Psychological Responses to Social Change: Human Development in Changing Environments. Berlin: DeGruyter, 1995.

Zahn-Waxler, C., Chapman, M., and Radke-Yarrow, M. (eds.). Aggression and Altruism: Biological and Social Origins. Cambridge: Cambridge University Press, 1986.

Zumkley, H. "Stability of Individual Differences in Aggression." In A. Fraczek and H. Zumkley (eds.), Socialization and Aggression. Berlin: Springer, 1992.

Zumkley-Münkel, C. Erziehung aus der Sicht des Kindes. Internationale Hochschulschriften [Child Rearing from the Child's Perspective: International College Press]. Münster, Germany: Waxmann, 1994.

GISELA TROMMSDORFF is professor of developmental psychology and chair of the Department of Developmental Psychology and Cross-Cultural Studies in the Social Science Division of the University of Konstanz, Germany.

HANS-JOACHM KORNADT is professor of educational psychology and chair of the Department of Educational Psychology and Education in the Social and Environmental Psychology Division of the University of the Saar, Saarbrücken, Germany. 